\title{
EFFECT OF DIFFERENT LIGHT WAVE LENGTHS ON THE GROWTH AND OIL CONTENT OF CHLORELLA VULGARIS
}

\author{
El-Sayed, A.B ${ }^{1}$ and Olfat, M.A. Salem ${ }^{2}$ \\ 1-Algal Biotechnology Unit, National Research Centre, Dokki- Cairo, Egypt \\ 2- Botany and microbiology department, Faculty of Science, Helwan University, Egypt
}

\begin{abstract}
:
Cultures of Chlorella vulgaris were grown in fully transparent polyethylene bottles $20 \mathrm{~L}$ and exposed to different light colors (i.e.; yellow, green, blue, red and white) by covering the growth vessel with fully transparency colored Nylon sheets with fixed light quantity $(120 \mu . e)$, growth containers provide the desired light. Growth was performed with fully recommended media of BG-11. By the end of growth period (17 days), oils were also determined. Growth parameters including dry weight, total chlorophyll and carotenes were daily assessed. Growth parameters were varied due to the used containers color type. Yellow and white colors enhanced dry weight accumulation, despite inhibited chlorophyll accumulation. Maximum chlorophyll content was obtained by green light grown cultures followed by blue and red lights. Carotenoids were increased with all used colored light, but green light represented the lowest increase as compared with control culture at zero time. Concerning dry weight growth evaluation, maximum growth rate $\left(\mu_{\max }\right.$.) was found to be the highest with cultures exposed to yellow color followed by white color. On the contrast, a negative relationship was observed with cultures that exposed to red light. As for total chlorophyll, slight differences were observed. Regarding carotenes, green and red colors represented the lowest, while white, yellow and blue colors had a little difference. The oil content was found to be slightly associated with carotenoids. White color container represented the maximum oil content following by the blue and yellow color. Oil content was closely related to carotenes content and maximum oil content was observed with yellow light grown alga (12.7\%), followed by $10.02 \%$ of blue light comparing with $9.4 \%$ of white light (control) and $9.34 \%$ of red light. The lowest oil content was observed with green light that gave $8.22 \%$.
\end{abstract}

Key words: Chlorella vulgaris - Light color - Dry weight - Total chlorophyll Carotenoids - Oil content

\section{Introduction}

Most of photosynthetic organisms including algae can acclimate to the ambient environmental light by changing their pigmentation system. Changes in pigmentation in photosynthetic organisms in response to light quality have been termed chromatic adaptation (Grossman et al., 1993).Rhythms of photosynthetic

\footnotetext{
*Correspondent author: email: olfatabdelhamed@yahoo.com
}

(ISSN: 1110-8649) 
capacity was found to be algae dependent, where it was maximized in white light in unicellular algae such as Lingulodinium polyedrum (Hastings et al., 1961) or Euglena sp. (Walther and Edmunds, 1973) or in red light in the filamentous brown alga Ectocarpus sp. (Schmid et al., 1992). Chlorella has much higher utilization rate (10-20\%) of light energy for the photosynthesis when compared to common plants (Zhang et al., 2000).

Light supply within the water column is a critical factor that also affects phytoplankton production and species composition in lakes. Although the abundance of many species is greatest in the epilimnion, where irradiance is greatest, other species including several algal flagellates are adapted to deeper waters (Lund and Reynolds, 1982). Red light increases carotenoid synthesis and chlorophyll fluorescence of Dunaliella bardawil (Sánchez-Saavedra et al., 1996).

Planktonic algae absorb blue light most strongly, and green light most weakly. The blue light absorption by algae strengthens the combined absorption effects of water and planktonic algae of that region. Light qualities affect the ultrastructure of Chlorella

Compared to red light cells, blue light cells exhibited higher photosynthetic rates per chlorophyll molecule and contained less chlorophyll per dry weight. Blue light stimulated the content of soluble protein as well as that of soluble carbohydrates. The combined absorption effect shows a sharp peak, in the red light spectral region $(600-700 \mathrm{~nm})$ when chlorophyll-a concentration is greater than $2.0 \mathrm{mg} . \mathrm{m}^{-3}$ and when the chlorophyll-a concentration is less than $2.0 \mathrm{mg} . \mathrm{m}^{-3}$, the combined absorption effect is not selective. The main cause of water color shift in the ocean is the absorption of blue light by planktonic algae (Shengguang et al., 1991).The absorbance properties of pigments facilitate their qualitative and quantitative analyses (Nusch, 1980; Sartory, 1982) and it was determined that the pigment level was influenced by limiting factors such as highlight, lack of nitrogen and limited nutrient (Greene et al., 1991 ; Collier and Grossman, 1992).

When Dunaliella was exposed to high light intensity of blue light, photoinhibition of $\mathrm{O}_{2}$ evolution, photo-destruction of carotenoids in the order 9-cis- $\beta$ carotene, all-trans- $\beta$-carotene, chlorophyll and finally the destruction of the cell were occurred (Ben-Amotz et al., 1989). Sequencly, the initial oil might be quantitavely and qualitatively varied. In commerce, production of $\beta$-carotene is controlled by numerous stress factors like high light intensity, high salinity, 
temperature and availability of nutrients and an inverse relationship exists between $\beta$-carotene content and the specific growth rate of Dunaliella (Raja $\boldsymbol{e t}$ al., 2007).

Exposure to low percentage of far red light did not decrease of growth rate of Chaetoceros sp. (Sánchez -Saavedra and Voltolina, 2006). It has also been observed that the accumulation of $\beta$-carotene and its isomeric ratio are strongly dependent on the light intensity and the quality of light used (Senger et al., 1993). In addition to the visible wavelength, ultraviolet (UV) radiation also affects $\beta$ carotene production.

Chlorophyll a content relating to the pigment level was almost the same in all algae groups, but chlorophyll $\mathrm{b}$ and $\mathrm{c}$ changed, Also the carotene level varied depending on the algae species and environmental conditions as there was an increase in the carotene level under some stress conditions (Martin et al., 1991 and Grung et al., 1992).Illumination is the most expensive factor of algae production during indoor growth (El-Sayed, 2007) and blue light tends to yield the highest oil production by Chlorella sp. and Saccharomyces (Shu et al., 2012). The lipid contents of the three Nannochloropsis sp., N. salina, N. oceanica, and N. oculata and bio-mass increased by using LED light than with ordinary fluorescent light using a two-phase culture system and the high lipid production wasobtained under green LED light stress in the second phase of the two-phase culture (Chae et al., 2016).

The current work was achieved to determine the color container effect on algal growth in terms of dry weight, pigmentation and oil content that can increase outdoor productivity rate through controlling light containers or source during night illumination.

\section{Materials and Methods}

\section{Alga and growth conditions}

The green alga Chlorella vulgaris (NRC) was early grown on fully saturated BG-II growth medium containing $17.6 \mathrm{mM}$ nitrogen (Stainer et al., 1971) to obtain the proper inoculum under white light. Illumination of white color was provided from 40w fluorescent lamps. Aeration was done by dried compressed air. The formed inoculum was harvested by cooling centrifuge and washed three times by glass bi-distilled water and then inoculated within 
polyethylene bottles containing five liters of fully saturated BG-II growth medium. In three replicates, polyethylene bottles were covered by $0.1 \mu$ fully transparent Nylon sheet. Sheet colors used were yellow, blue, green and red. Control cultures were performed within the colorless polyethylene bottles. Each color treatment was carried out in three replicates.

\section{Growth determination}

Daily sampling and determination of dry weight, total chlorophyll and carotenes were employed. Dry weight was measurement by filtering a defined volume of the algal slurry $(5-10 \mathrm{ml})$ over pre-weighted dried membrane filter $(0.45 \mu \mathrm{m})$. Filters were dried at $105^{\circ} \mathrm{C}$ for 30 minutes, kept over anhydrous calcium chloride till room temperature and then re-weighted. The difference between weights monitored the net dry weight of the grown alga within defined sampling time. Chlorophyll was extracted from the pre-centrifuged algal bulk by 95\% DMSO (Burnison, 1980). Chlorophyll absorbance was measured at $666 \mathrm{~nm}$ and concentration was calculated (mg. $\mathrm{g}^{-1}$ ) according to Seely et al.(1972).To recover carotenes, saponification was performed by $5 \% \mathrm{KOH} / 30 \% \mathrm{MeOH}$ and the residual was re-extracted by DMSO after the addition of 5 drops of concentrated acetic acid (Boussiba et al., 1992). Carotenes absorbance was measured at $468 \mathrm{~nm}$ and concentration was calculated (mg. $\left.\mathrm{g}^{-1}\right)$ according to Davis (1976). Growth analysis; mainly growth rate $(\mu)$ and percentage increase (y \%) was performed using the methods adopted by Wolf and Carson (1973). Oil content was determined by $n$-hexane/isopropanol (3:2) extraction using Soxhelt technique.

\section{Results and Discussion}

\section{Light color affecting dry weight}

Among the different light color containers used, yellow color was found to be the most effective color on growth dry weight accumulation, however white color was early considered as the common used color especially for inoculum preparation or indoor cultivation The obtained result was found in harmony with Sebastián et al., 2013 which showed that $C$. vulgaris does not adapt production of 
their photosynthetic pigments to absorb light from a wavelength spectrum different from one that they would normally be exposed to. Other colors (blue, white and red) resulted in somewhat less biomass production. Motile cells released in continuous green or blue lights, but not in red one were really observed (Cepak et al., 2006).

On the other hand, Barghbani et al. (2012) reported that light color indicated the least significant effect on Chlorella vulgaris production among different examined factors including salinity, temperature, iron and light color. They also added that yellow and blue lights increased the algal growth; however salinity ( $\mathrm{NaCl}$ concentration) had the highest impact on the biomass production.

Regardless yellow color, white color surpasses blue, green, and red light. In addition, red light seems to be having no effect as compared with zero point dry weight (Fig. 1). The effect of light; as a whole; on algal growth composition is referred to the given wavelength that varied on their energy content. This hypothesis could be confirmed by other earl investigations. Total power of emission of the white lamps is higher than those of the other light sources, because of the differences in the respective light spectra.

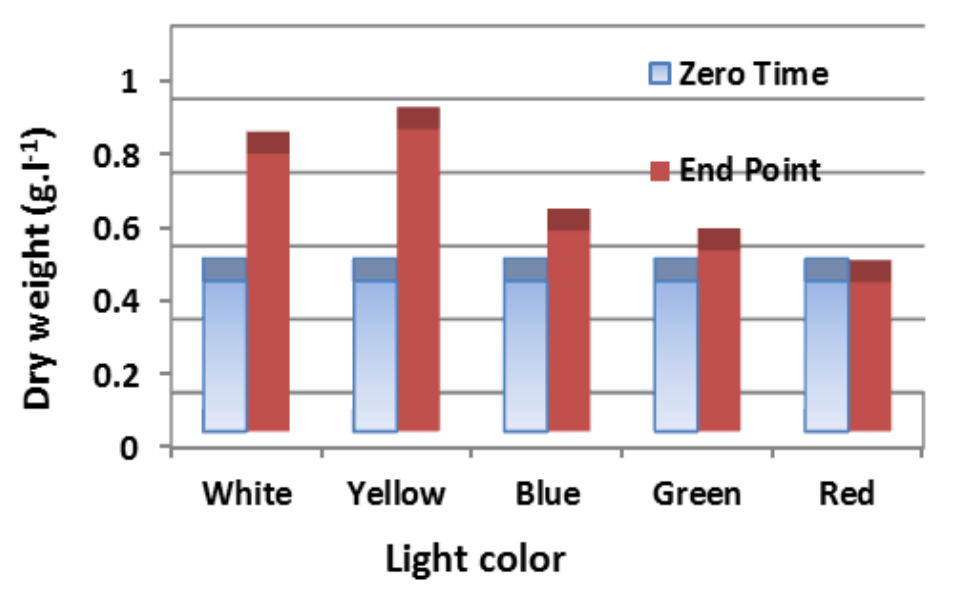

Fig. 1.Dry weight of Chlorella vulgaris as grown under different light color containers. 
On the contrary, red LED light was found to be the most effective in cell division and dry weight accumulation, while blue LED light was the most effective in cell enlargement (Koc et al., 2013).

The rate of percentage increase was listed in Table (1); showing the slight decline that observed with red light. Maximum growth dry weight was obtained with yellow light, while negative relationship was observed with red light. Thus, it could be concluded that yellow light seems to be the ambient and universal color of sun light that naturally enhances the most surface grown algae in their habitats. Such phenomenon is much desired for biomass production that aims to produce the maximum dry weight within define area or growth volume. To meet that, sun energy must be used all over the day and store to use by night illumination by electric yellow white sources. Moreover, the differences in growth rates and in biomass production should be considered as the effect of the differences in light absorption caused by those of spectral emission (Sánchez-Saavedra and Voltolina, 2006).

Table 1.Percentage increase and average growth rate ( $\mu$ avr.) of some growth metabolites of Chlorella vulgaris as affected by light color.

\begin{tabular}{|c|c|c|c|c|c|c|}
\hline \multirow{2}{*}{$\begin{array}{c}\text { Light } \\
\text { color }\end{array}$} & \multicolumn{2}{|c|}{ Dry weight } & \multicolumn{2}{c|}{ Total chlorophyll } & \multicolumn{2}{c|}{ Total carotene } \\
\cline { 2 - 7 } & $\mathrm{y} \%$ & $\mu_{\mathrm{avr}} \cdot$ & $\mathrm{y} \%$ & $\mu_{\mathrm{avr}} \cdot$ & $\mathrm{y} \%$ & $\mu_{\text {avr }}$ \\
\hline White & 84.6 & 0.61 & 657 & 0.12 & 801 & 0.13 \\
Yellow & 100.8 & 0.70 & 642 & 0.12 & 682 & 0.12 \\
Blue & 33.3 & 0.29 & 883 & 0.13 & 774 & 0.13 \\
Green & 20.3 & 0.19 & 989 & 0.14 & 84 & 0.04 \\
Red & -0.8 & -0.01 & 885 & 0.13 & 462 & 0.10 \\
\hline
\end{tabular}

\section{Total chlorophyll}

Chlorophyll content (mg.g-1) was found to be more affected by light color rather than dry weight accumulation as a variation between the define growth period. In addition, an opposite manner was found verses dry weight accumulation. Despite yellow light surpasses all other color used in concern dry weight accumulation, green color was found to be the more effective light color affecting chlorophyll accumulation (Fig. 2).

Values of percentage increase were listed in Table (1). However percentage increases presented a great variation (642-989\%); growth rate showed the minor 
variation (0.12-0.14 g.d $\left.\mathrm{d}^{-1}\right)$. The effect of light color on chlorophyll formation might be ascribed to the energy coming from the used color in concern wavelength. Total chlorophyll per volume of Chlamydomonas and Chlorella was increased $20 \%$ while the chlorophyll a/b ratio was decreased during the adaptation period (10 days) in blue light. In red light no change was observed regarding total amount of chlorophyll or chlorophyll a/b ratio (Hess and Tolbert, 1967). Green color showed high chlorophyll content, these results agreed with Mattos et al., 2015 they concluded that weakly absorbed colors of light such as green results in a higher photosynthetic efficiency for high density cultures of Scenedesmus bijuga.

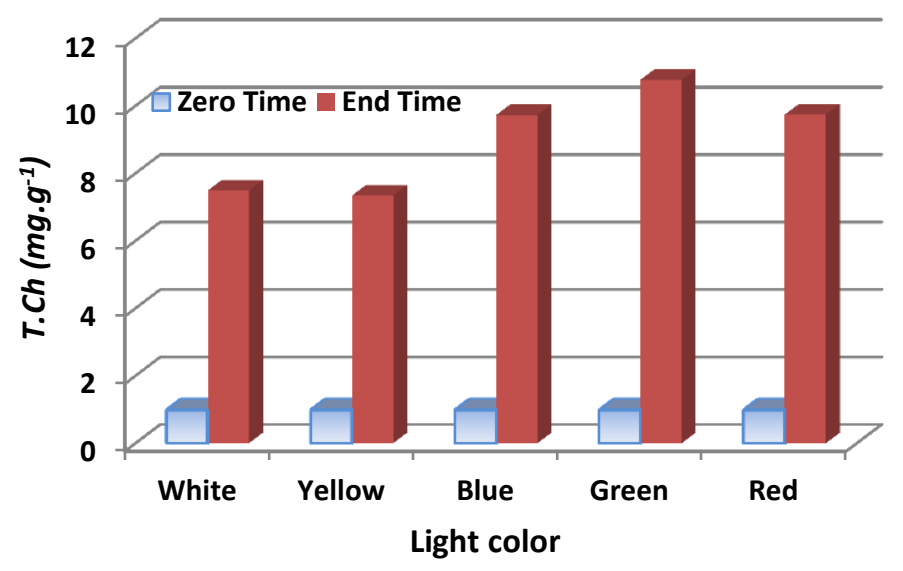

Fig. 2.Total chlorophyll of Chlorella vulgaris grown under different light color containers.

\section{Total carotenoids}

The role of carotene pigments in algae has been suggested as a passive light protecting filter and has got the role of accessory pigments transferring energy and oxygen (Yong and Lee, 1991and Bidigare et al., 1993).Carotene content (mg.g1) of Chlorella vulgaris represented another different manner as growth response was compared with those of dry weight and total chlorophyll under different light color. White light possesses the most enhancing effect. Despite green light 
increases chlorophyll accumulation, it was represented the lowest increase of carotene accumulation (Fig. 3).

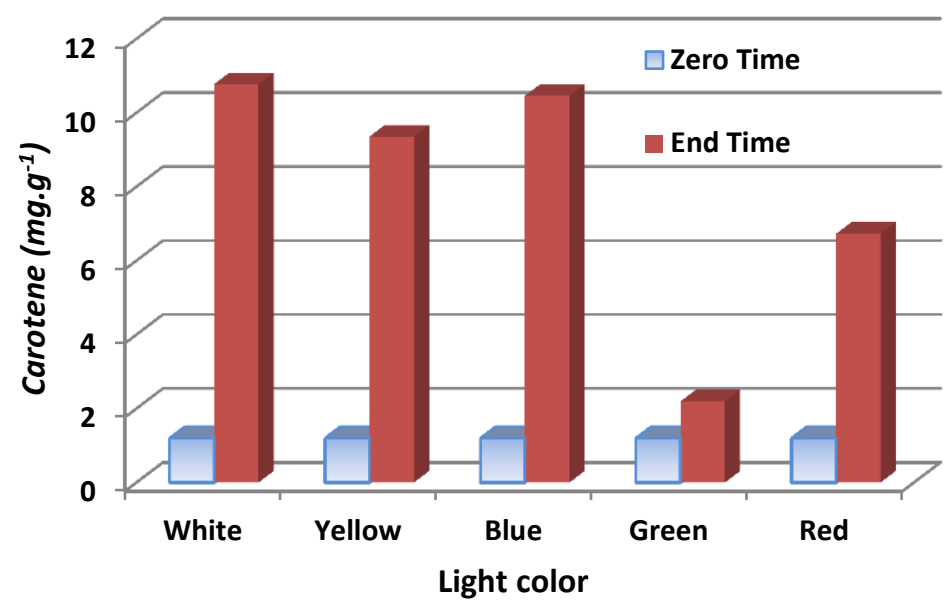

Fig. 3. Total carotenes of Chlorella vulgaris grown under different light color containers.

Numerous factors have been shown to induce massive carotenoid accumulations and these include high photosynthetic photon flux density (Brown et al., 1997); far red light and nutrient limitation conditions (Borowitzka and Borowitzka, 1988). All of these factors are known to accumulate carotenoid content along with a reduction in the growth rate (Radmer, 1996). Thus, an inverse relationship exists between $\beta$-carotene content and the specific growth rate (Ben-Amotz et al. 1982; Raja et al., 2007). Far red light may affect the growth rates of marine phytoplankton (Lipps, 1973) and increases carotenoid synthesis as well as chlorophyll fluorescence of Dunaliella bardawil (Sánchez-Saavedra $\boldsymbol{e t}$ al., 1996).

In general, protein and chlorophyll content are the most influenced components that sharply decreased, while others like carbohydrates, lipids and carotenoids tended to increase. In all cases, dry weight failure was found to be closely related to both chlorophyll and protein decomposition. Container light might affect algal growth by interprets the penetrated light wave length to energy. Consequently, cell component could be fixed under different container color rather than the exposure light color. As the verse relationship between dry weight 
and chlorophyll with the opposite between dry weight-chlorophyll and carotenes, such results were listed in Table (2).

\section{Growth metabolites ratios}

The relationships of growth metabolites (dry weight, chlorophyll and carotenes) were early suggested. Increasing of dry weight was usually accompanied by cell protein content increases. Under non-favorable conditions, growth profile severely changed in relation to stressor factor and stress degree. The composition of microalgae may be modified using different light sources (Mercado et al., 2004), In addition, Red light is also responsible for high carbon fixation with high respiratory rate the wavelength may influence cell composition relative to protein, polysaccharides, and lipids (Riviken, 1989).

Table 2.Dry weight: pigments ratios ( $\mathrm{mg} / \mathrm{mg})$ of Chlorella vulgaris as affected by light color.

\begin{tabular}{|c|c|c|c|c|}
\hline & & D.w/Ch. & D.w/Car. & Ch./Car. \\
\hline Zero tim & & 39.08 & 685.6 & 17.54 \\
\hline & White & 23.04 & 140.2 & 6.04 \\
\hline$\overline{3}$ & Yellow & 25.70 & 175.3 & 6.82 \\
\hline . & Blue & 12.89 & 104.2 & 8.09 \\
\hline $\bar{Z}$ & Green & 10.57 & 451.0 & 42.67 \\
\hline & Red & 9.57 & 120.4 & 12.59 \\
\hline
\end{tabular}

\section{Oil content}

Oil content in relation to growth container color was severely acute and mostly associated with carotenoids vis chlorophyll content. Yellow color growth container resulted in the highest oil content (12.7\%). Here, the low initial oil content might be ascribed to the enhancing effect of yellow color on vegetative growth and the rising of protein content at the expense of oil level. Colors triggered carotenoids accumulation effect might go back to the initial energy that accelerate chlorophyll decomposition. 


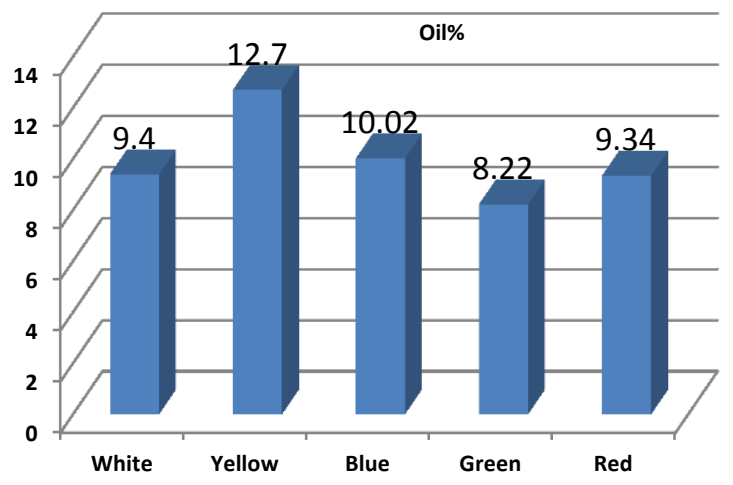

Fig. 4. Oil content of Chlorella vulgaris grown under different light color containers.

Fluorescent light produced more cells than red or natural light with same biomass with Spirulina platensis and Nannochloropsis oculata referring that light wavelength will impact cell size, reproduction, and composition which determines the value the algae has as a bio-fuel (Chen and Lee, 2012).

Several studies reported the growth of microalgae in different light wavelengths. Red $(600-700 \mathrm{~nm})$ and blue lights $(400-500 \mathrm{~nm})$ stimulate the growth of microalgae, and the growth rates and lipid content of the microalgae differ with light intensity (Blair et al., 2014). Chae et al., 2016 showed that the high lipid production of three Nannochloropsis sp. in two-phase culture was obtained under green LED light stress in the second phase of the two-phase culture. The two-phase culture contributed to an increase in lipid productivity by separating the cell growth and lipid production with different LED wavelengths in the microalgae culture. Commercially, factors affecting carotenoids and oils content including light, salinity and nutrient starvation are so hard in implication within open ponds due to insufficient light penetration. Such effect could enhance using photobioreactors. In this case, night illumination of open ponds by desired led light could suggest this result. Wilhelm et al., 1985 showed that under electron microscopy, blue light cultures showed enlarged cells, thinner cell walls and lower starch content than red light cells. Under blue light, the degree of stacking of the thylakoid membranes was significantly lower than under white or red light conditions. The blue LED is an efficient energy source for high density 
culture of $C$. vulgaris as compared to white fluorescent light because it reduce the cultivation time to 8 days compared to 10 days under white fluorescent light in addition to its low power consumption, less heat dissipation and deep penetration in the cultivation system (Atta et al., 2013).

\section{Conclusion}

Color of growth container effect on different cell metabolites was varied due to the received light by grown algal cell and the high obtained biomass under define exposure light is not conditioned by the increasing of other determined cell metabolites including chlorophyll and carotenes. The highest obtained biomass with adequate oil content is more efficient rather than those lower biomass with high oil content.

\section{Acknowledgment}

This research work has been carried out as a part of activities of Algal Biotechnology Unit, National Research Centre, Dokki, Cairo, Egypt, (Prof. Dr. Abo El-Khair B. El-Sayed). The authors express thanks to all other stuff members.

\section{References}

Atta M., Idris A., Bukhari A and Wahidin S. (2013). Intensity of blue LED light: A potential stimulus for biomass and lipid content in fresh water microalgae Chlorella vulgaris Bioresource Technology 148 (2013) 373378

Barghbani, R. ;Rezaei, K. and Javanshir, A. (2012). Investigating the Effects of Several Parameters on the Growth of Chlorella vulgaris Using Taguchi's Experimental Approach. International Journal of Biotechnology for Wellness Industries, 1, 128-133.

Ben-Amotz, A.; Katz, A. and Avron, M. (1982).Accumulation of $\beta$-carotene in halotolerant algae: purification and characterization of $\beta$-carotene rich globules from Dunaliella bardawil (Chlorophyceae). J. Phycol.; 18:529-537. 
Ben-Amotz A. Shaish A. and Avron M. (1989).Mode of action of massively accumulated $\beta$-carotene of Dunaliella bardawil in protecting the algae against damage by excess irradiation. Plant Physiol. 91: 1040-1043.

Bidigare, R.R.; Ondrusek, M.E.; Kennicutt, M.C. and Harvey, H.R. (1993).Evidence for a photoprotective function for secondary carotenoids of snow algae. J. Phycol.; 29, 427-434.

Blair, M.F. ,Kokabian B., Gude V. G. (2014).Light and growth medium effect on Chlorella vulgaris biomass production. Journal of Environmental Chemical Engineering, 2(1), pp. 665-674.

Borowitzka, M. A., and Borowitzka, L. J. (1988).Limits to growth and carotenogenesis in laboratory and largescale outdoor cultures of Dunaliellasalina. In: Stadler, T., Mollion, J., Verdus, M. C., Karamanos, Y., Morvan, H., and Christiaen, D., eds. Algal Biotechnology. Elsevier Applied Science, Barking, U. K., pp. 371-81.

Boussiba, S.; Fan, L. and Vonshak, A. (1992).Enhancement and determination of astaxanthin accumulation in green alga Haematococcus pluvialis. Methods in Enzymology, 213, Carotenoids Part A, Lester Packer (ed.), Academic Press: 386-371.

Brown M.R.; Jeffrey S.W.; Volkman J.K. and Dunstan G.A. (1997).Nutritional properties of microalgae for mariculture. Aquaculture 151:315-331.

Burnison, B. K. (1980). Modified dimethyl sulfoxide (DMSO) extraction for chlorophyll analysis of phytoplankton.Can. J. Fish. Aquat. Sci.; 37:729733.

Cepak, V.; Pribyl, P. and Vitova, M. (2006).The effect of light color on the nucleocytoplasmic and chloroplast cycle of thr green chlorococcal alga Scenedesmus obliquus. Folia Microbial.; 51(40); 342-348.

Chae H.R.,,Chang H K. ,Jang H J., Gwi T J. and Sung K K. (2016) Effects of light-emitting diodes (LEDs) on the accumulation of lipid content using a two-phase culture process with three microalgae. Bioresource Technology $212: 254-261$

Chen Y. C. and Lee, M. C. (2012).Double-power double-hetrerostructure light emitting diodes in microalgae, Spirulina platensis and Nannochloropsis oculata, cultures. Journal of Marine Science and Technology 20(2), 233236. 
Collier, J.L. and Grossman, A.R. (1992).Chlorosis induced by nutrient deprivation in Synechocccus sp. J. Bacteriol.; 174:4718-4726.

Davis, B. H. (1976). Carotenoids. In: Chemistry and Biochemistry of Plant Pigments. $2^{\text {nd }}$ Eddition, vol.2. ed. Goodwin. T. W. pp.38-165.Academic Press.

El-Sayed, A. B. and El-Fouly, M. M. (2005).Recovery of outdoor mass culture bleached Scenedesmus sp. Pakistan Journal of Biological Sciences, 8,3: 470-474.

El-Sayed, A.B. (2007). Economizing of intensive outdoor mass production of the green alga Scenedesmus sp. Egyptian J. of Phycology, 8, 85-96.

Greene, R.M.; Gerder, R.J. and Falkowski, P.G. (1991).Effect of iron limitation on photosyntesis in a marine diatom. Limnol. Oceanogr.; 36:1772-1782.

Grossman, A.R.; Schaefer, M.R.; Chiang, G.G. and Collier, J.L. (1993). The Phycobilisome, a Light-Harvesting Complex Responsive to Environmental Conditions. Microbiological Reviews, 57, 3:725-749

Grung, M.F.; D'souza, M.L. and Borowitzka, M. (1992).Algal Carotenoids 1.Secondary Carotenoids.J. Appl. Phycol.; 4,165-171.

Hass, J.L. and Tolbert, N.E. (1967). Changes in chlorophyll a/b ratio and products of $14 \mathrm{CO} 2$ fixation by algae grown in blue or red light. Plant Physiol. 42, 1123-1130.

Hastings, J.W.; Astrachan, L. and Sweeney, B. M. (1961).A persistent daily rhythm in photosynthesis. J. Gen. Physiol.; 45:69-76.

Koc, C.; Anderson G. A. and Kommareddy, A. (2013). Use of Red and Blue LEDs and Fluorescent Lamps as Light Sources to Grow Microalgae in a Photobioreactor (PBR). The Israeli Journal of Aquaculture- Bamidgeh, IJA_64.2013.797, 11 pages

Lipps, M.J. (1973).The determination of the far-red effect in marine phytoplankton. J. Phycol.; 9, 237-242.

Lund, J. W. G. and Reynolds, C. S. (1982).The development and operation of large limnetic enclosures in Blelham Tarn, English Lake District, and their contribution to phytoplankton ecology. Progress in Phycological Research 1:1-65.

Martin, J.H.; Gordon, R.M. and Fiztwater, S.E. (1991). The Case for Iron. Limnol. Oceanogr.; 36: 1793-1803. 
Mattos E.R., Singh M., Cabrera M.L., Das K.C., (2015) Enhancement of biomass production in Scenedesmus bijuga high-density culture using weakly absorbed green light, Biomass Bioenergy 81: 473-478

Mercado, J.M., Sa'nchez-Saavedra, M.P., Correa-Reyes, J.G.,Lubia'n, L., Montero, O., Figueroa, F.L., (2004).Blue light effect on light absorption characteristics and photosynthesis of five benthic diatom species. Aquat. Bot. 78, 265-277.

Nielsen, M. V. and Sakshaug, E. (1993).Photobiological studies of Skeletonema costatum adapted to spectrally different light regimes. Limnol. Oceanogr.; 38:1576-81.

Nusch, E.A. (1980).Comparison of Methods for Chlorophyll and Phaeo-pigment Determination. Arch. Hydrobiol. Limnol.; 14: 14-36.

Radmer RJ (1996). Algal diversity and commercial algal products. Bioscience, 46(4),263-277.

Raja.R.; Hemaiswarya, S.andRengasamy, R. (2007). Exploitation of Dunaliella for $\beta$-carotene production. Appl Microbiol Biotechnol.; 74:517-523.

Rivkin, R.B. (1989). Influence of irradiance and spectral quality on the carbon metabolism of phytoplankton. I. Photosynthesis, chemical composition and growth. Mar. Ecol. Prog. Ser.; 55: 291-304.

Sánchez-Saavedra, M.P. and Voltolina, D. (2006).The growth rate, biomass production and composition of Chaetoceros sp. grown with different light sources. Aquacultural Engineering, 35:161-165.

Sánchez-Saavedra, M.P.; Jiménez, C. and Lo'pez-Figueroa, F. (1996).Far red light inhibit growth but promotes carotenoid accumulation in the green microalgae Dunaliella bardawil. Physiol. Plant.; 95:419-423.

Sartory, D.P. (1982).Extraction of Chlorophyll a from Freshwater Phytoplankton for Spectrophotometric Analysis. M. Sc. Thesis. Univ. Orange free state, Bloemfontein, Republic of S. Africa.

Schmid, R.; Forster, R. and Dring, M.J. (1992).Circadian rhythm and fast responses to blue light of photosynthesis in Ectocarpus (Phaeophyta, Ectocarpales). II. Light and $\mathrm{CO}_{2}$ dependence of photosynthesis. Planta 187:60-66.

Sebastián MR, Gabriel JCR and Voroney R. P (2013). Effect of Carbon Dioxide Concentration on the Growth Response of Chlorella vulgaris Under Four Different Led Illumination International Journal of Biotechnology for Wellness Industries, 2: 125-131 
Shu, C.-H., Tsai, C.-C., Liao, W.-H., Chen, K.-Y., Huang, H.-C. (2012)Effects of light quality on the accumulation of oil in a mixed culture of Chlorella sp. and Saccharomyces cerevisiae. Journal of Chemical Technology \& Biotechnology 87, 601-607

Seely, G. R.; Doncan, M. J. and Widaver, W. E. (1972).Preparative and analytical extraction of pigments from brown algae with dimethyl sulfoxide. Mar. Biol., 12: 184-188.

Senger, H.; Wagner, C.; Hermsmeier, D.; Hohl, N.; Urbig, T. and Bishop, N.I. (1993).The influence of light intensity and wavelength on the contents of $\alpha$ and $\beta$-carotene and their xanthophylls in green algae. J. Photochem. Photobiol. Biol.; 18:273-279.

Shengguang,Y.; Daying, X.; Xiaolong, Y. and Jun, Z. (1991).Effect of algae and water on water color shift. Chin. J. Oceanol. Limnol.; 9(1): 49-56.

Stainer.R.Y.; Kunisawa, R.; Mandel, M. and Cohin-Bazire, G. (1971).Purification and properties of unicellular blue-green algae (order Chrococcales). Bacteriol Rev.; 35:171-205.

Walther, W. G. and Edmunds, L. N. (1973).Studies on the control of the rhythm of photosynthetic capacity in synchronized cultures of Euglena gracilis (Z). Plant Physiol.; 51:250-258.

Wilhelm C., Kramer P. and WildA. (1985).Effect of different light qualities on the ultrastructure, thylakoid membrane composition and assimilation metabolism in Chlorella fusca Physiol. Plant. 64, 359-364

Wolf D. D. and Carson E. W. (1973). Growth analysis, Journal of Agronomic Education. 2:39-42.

Yong, Y.Y.R. and Lee, Y.K. (1991).Carotenoids Play a Photoprotective role in the cytoplasm of Haematococcus lacustris (Chrolophyta). Phycologia, 30: 257-261.

Zhang, F.; Kabeya, H.; Kitagawa, R. and Hirotsu, T. (2000).An exploratory research of PVC-Chlorella composite material (PCCM) as effective utilization of Chlorella biologically fixing $\mathrm{CO}_{2}$. J. Mater. Sci.; 35: 26039. 


\title{
تأثير الاطوال الموجية المختلفة للضوء على نمو ومحتوى الزيت لطحلب \\ Chlorella vulgaris
}

\author{
أبو الخير بدوى السيد ' - القت عبد الحميد سالم \\ 1 - وحدة النكنولوجيا الحبوية للطحالب - المركز القومى للبحوث - الدقى \\ r- قسم النبات و الميكروبيولوجى - كلية العلوم - جامعة حلوان
}

تم زراعة طحلب Chlorella vulgaris في زجاجات بولي ايثيلين شفافة تماما (20لتر) ثم تعرضت لألوان مختلفة من الضوء (الأصفر والأخضر والأزرق والأحمر والأبيض) من خلال تغطينها

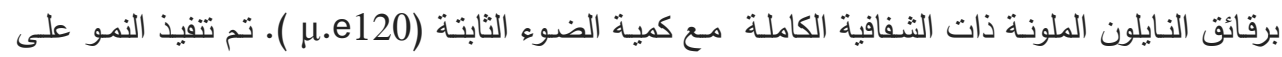

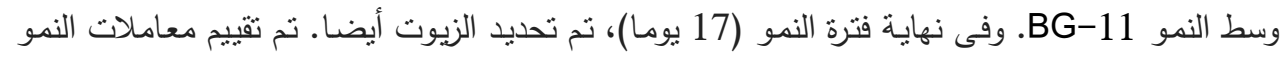

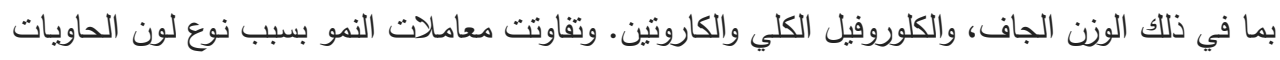

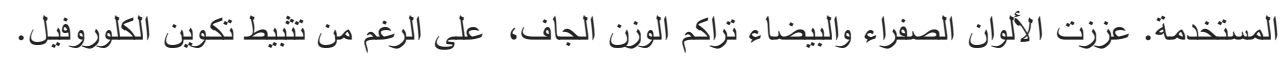

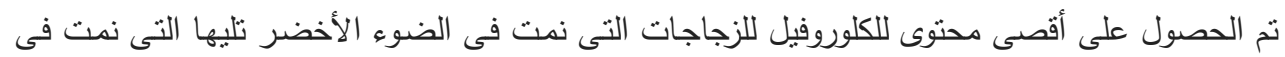

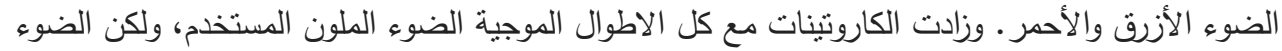

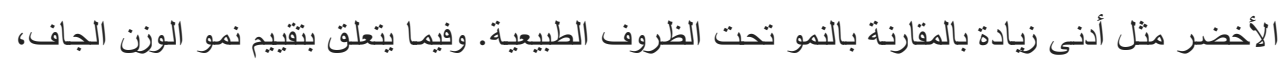

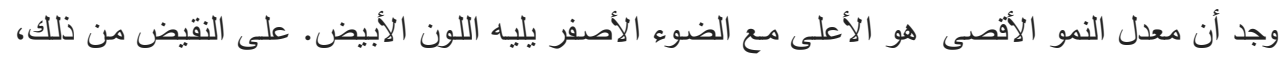

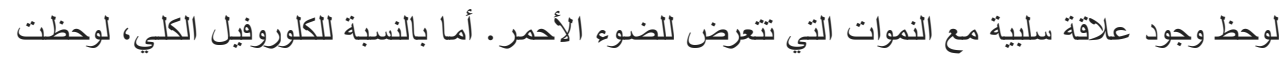

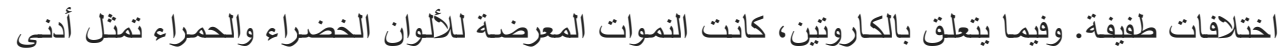

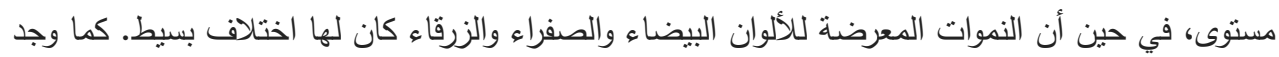

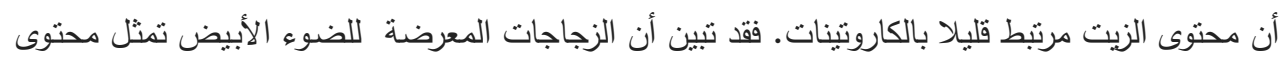

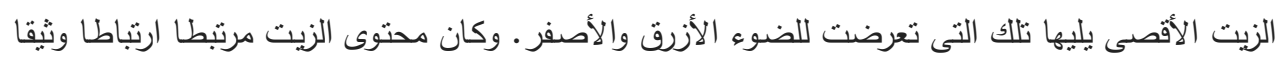

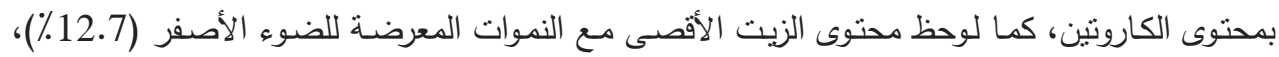

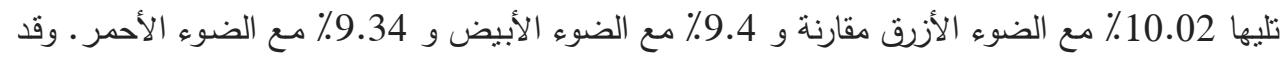

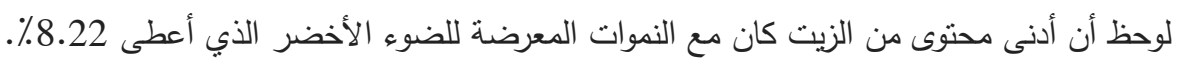

